\title{
Patrick Sommier, la MC93, et le Standard Idéal
}

\section{Patrick Sommier}

\section{(2) OpenEdition \\ Journals}

\section{Édition électronique}

URL : http://journals.openedition.org/shakespeare/1649

DOI : 10.4000/shakespeare.1649

ISSN : 2271-6424

Éditeur

Société Française Shakespeare

\section{Édition imprimée}

Date de publication : 1 mars 2011

Pagination : 273-277

ISBN : 2-9521475-7-4

\section{Référence électronique}

Patrick Sommier, «Patrick Sommier, la MC93, et le Standard Idéal », Actes des congrès de la Société française Shakespeare [En ligne], 28 | 2011, mis en ligne le 15 février 2011, consulté le 01 mai 2019. URL : http://journals.openedition.org/shakespeare/1649; DOI : 10.4000/shakespeare.1649 


\section{Shakespeare et la Cité}

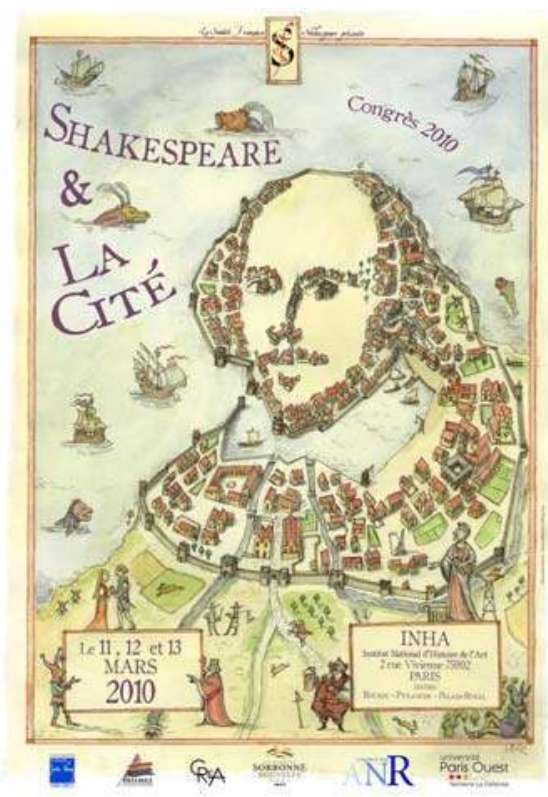

actes du Congrès

organisé par la

SOCIÉTÉ FRANÇAISE SHAKESPEARE

les 11,12 et 13 mars 10

textes réunis par

Pierre KAPITANIAK

sous la direction de

Dominique GoY-BLANQUET 
COUVERTURE :

Edouard Lekston 2010

conception graphique et logo

Pierre Kapitaniak

\section{(C) 2010 Société Française Shakespeare \\ Institut du Monde Anglophone}

Université de Paris III - Sorbonne Nouvelle

5 rue de l'École de Médecine 75006 Paris

www.societefrancaiseshakespeare.org

Tous droits de traduction, de reproduction et d'adaptation réservés pour tous les pays 


\section{PATrick Sommier, LA MC93, ET LE STANDARD IDÉAL}

$\mathrm{S}$ hakespeare et la Cité ? Disons plutôt ce qu'il reste de théâtre dans ce qu'il reste de la Cité. Ce petit coin de Paris a été plein de vie, proche de l'ancien quartier populaire des Halles, autrefois le cœur vivant de la Cité, quelque chose qui paradoxalement renait peutêtre dans les faubourgs, les banlieues qu'on appelle étrangement «les cités ».

La MC 93 a ouvert ses portes en mai 1980 avec un spectacle brésilien, Macunaima, et pris vraiment son envol avec René Gonzalez, en 1985. C'était un rêve d'implanter dans ces banlieues des théâtres, des maisons de culture, à Sartrouville, Villejuif, Aubervilliers, Nanterre, Saint-Denis et tant d'autres, des territoires très différents de ce qu'ils sont aujourd'hui. Un rêve de compagnonnage entre culture et politique, dominé par le Parti Communiste Français qui souhaitait, à l'époque mais plus maintenant, cette vitrine de la culture, cette relation privilégiée avec les intellectuels. Le théâtre était le vecteur principal de cette complicité. Je me souviens de salles entières achetées, par exemple pour Les Bains de Maïakovski dans une mise en scène de Vitez, par la Fédération de Seine-Saint-Denis du Parti Communistes, ou une foule d'associations comme « Travail et Culture », qui fondaient un public militant. C'est dans ces nombreux théâtres que s'est lancée l'aventure moderne du théâtre après la guerre. C'est là qu'ont commencé Bernard Sobel, Patrice Chéreau, Jean-Pierre Vincent, Ariane Mnouchkine, Antoine Vitez. Cet étrange décentrement de la ville était dû aussi à des contraintes techniques. Peu de plateaux dans Paris étaient capables d'accueillir des expériences théâtrales modernes, c'était l'occasion d'en créer, à Nanterre, notamment et Bobigny, bien sûr. Les autres étaient plus modestes. Les théâtres de Paris étaient encore très dominés par le "boulevard », ce théâtre bourgeois à la française sur lequel je ne jette d'ailleurs pas l'anathème. Soixante ans après la disparition de Copeau, Dullin, le théâtre se transporte dans cette Seine-Saint-Denis, un département très particulier, objet de lois d'exception pendant la guerre d'Algérie, fief du PCF, avec une histoire faite de guerres, de révolution industrielle, de vagues d'immigration 
(d'abord allemande, suisse, belge et kabyle), de crises économiques, de fermetures d'usines qui créent sa culture profonde. Une banlieue où tous les publics se mélangent, où se développe cette idée de "théâtre de proximité » qui n'a jamais existé sinon militant et encadré de partis politiques, syndicats et comités d'entreprises. Le public auquel on a affaire aujourd'hui est beaucoup plus volatile, se partage une palette de théâtres «favoris », ne se lie pas par des abonnements ou une fréquentation régulière.

Pourquoi Shakespeare à la MC93 ? C'est une évidence, donc une chose masquée, secrète, très difficile à extirper. Pourquoi un pommier donne-t-il des pommes ? Pendant les trente années d'existence de ce lieu, Shakespeare n'a pas été tout le temps une évidence. Il y a eu très peu de spectacles shakespeariens en mon absence, quand j'étais pour une saison française en Russie, puis une douzaine depuis mon retour, au minimum un par an, souvent des comédies. On ne peut pas travailler à Bobigny, au milieu des immeubles, d'un urbanisme assez inhumain, avec une centaine de langues parlées dans un rayon de deux kilomètres, comme on travaille ailleurs. Mais il ne s'agit pas de créer une culture d'apartheid pour un public considéré comme inculte, qui a souvent au moins deux cultures, sa culture d'origine et sa culture d'accueil. Au mieux ce public de Seine-Saint-Denis constitue trente pour cent de l'ensemble de notre public, chiffre très variable selon ce qu'on y fait. Nous avons à faire à au moins deux catégories de publics : celui qu'il faut initier au théâtre, et celui des amateurs de théâtre. Pour Shakespeare, des metteurs en scène comme Jean-Yves Ruf, Laurent Laffargue, Jean-Michel Rabeux accomplissent un travail de fond pour aller chercher, créer de nouveaux publics, travail vital pour tous les théâtres du monde. Le Standard Idéal s'adresse à un public beaucoup plus averti, avec des spectacles forts comme le Macbeth mis en scène par Jürgen Gosch, mort l'année dernière, ou Was irh wollt du jeune metteur en scène de Bochum, David Bösch, qui a ouvert la saison. C'est un festival très particulier parce qu'il n'essaie pas de présenter des spectacles susceptibles d'être ingérés, digérés par un public français. Il s'attache plus aux différences qu'aux points « communs », à ce qui passe facilement la frontière.

Pour répondre à votre question j'ai demandé à mes metteurs en scène pourquoi ils montaient Shakespeare. Il y eut chaque fois pour commencer un long silence. Rabeux, dont le Songe a été un moment 
marquant dans cette quête de nouveau public, m'a dit qu'il avait attendu trente-cinq ans avant de monter Shakespeare parce que pour lui c'était « important » Shakespeare. Mais vraiment pourquoi ? Long silence. Pour, je cite, «plonger à l'intérieur de la modernité. Lire Malvolio la nuit ça fait peur, c'est l'intégrisme qui interdira bientôt le théâtre (...) Dans une langue bouleversante, Shakespeare donne la liberté d'adapter, de penser, de mettre en forme, ça provoque, ça attaque les jeunes gens qui ne sont jamais allés au théâtre, c'est un accès ... à un public, c'est accéder au public, et pour le public, c'est accéder au théâtre. » C'est une des clés de la relation avec ce public à construire, qu'il faut amener par la main à faire ses premiers pas au théâtre.

J'avais vu l'Othello de Laurent Laffargue au Théâtre de Suresnes, dans une salle remplie de lycéens. Il se passait vraiment quelque chose entre le public et les comédiens, tous très jeunes, encore très vrais, généreux, pas truqueurs. C'était là ce " faire passer » « cet accès » dont parle Rabeux. Quand Jean-Yves Ruf a monté Mesure pour mesure l'hiver dernier, avec sa bande de comédiens et d'amis, je me suis rendu compte combien Shakespeare était cruel pour les comédiens. Cette bande, des prolétaires de l'école de Strasbourg payés au lance-pierre, ce fourmillement d'acteurs, formait un contraste frappant avec la maîtrise un peu « marque de fabrique » d'Eric Ruf qui vient de la Comédie-française, dans le rôle d'Antonio. C'était le seul qui ne s'intégrait pas dans cet ensemble « populaire » mis en scène par son frère.

Pourquoi Shakespeare? Mes souvenirs les plus anciens remontent à trente ans, je n'ai pas pu remonter plus loin. C'est une curieuse relation, qui tient de l'archéologie. Il ne nous parle ni du passé ni du futur, mais d'un présent qui englobe tout. Cette relation, à Bobigny, est évidente, elle touche au pouvoir, aux coups bas de la politique, au désir, au sexe, à l'amour, l'évidence de la vie quotidienne des enfants qui viennent écouter cela. Autre paradoxe, depuis dix ans, je n'ai pas montré un seul classique français. La complexité de Shakespeare est exactement le contraire de ce théâtre carré, raisonnable, rationnel, concret, complètement déphasé par rapport au tumulte de la société actuelle, multilingue. Jean-Yves Ruf, qui a mis en scène à la MC93 Comme il vous plaira, puis Mesure pour mesure, à la question "pourquoi Shakespeare » m'a répondu qu'il habitait à côté 
d'une forêt, qu'il voulait montrer la forêt, qu' « on ne comprend jamais complètement Shakespeare, et qu' il faut accepter ça [...] C'est une forêt où on se perd, complexe, polysémique, dans la jubilation de la langue, de la forme [...] On est toujours au bord du lapsus, à un endroit de la langue qui affole ». Nous avons besoin au théâtre de cette incertitude. Un jour j’ai demandé à Benno Besson de monter une pièce de Mishima, Le palais des fêtes. Quelques jours plus tard, il m'a dit « Écoute, j’ai lu ta pièce, mais tout est dit dedans, tout est écrit. Et quand tout est dit, il n'y a pas de théâtre possible. » Il avait parfaitement raison. Avec Shakespeare justement, cette part cachée, secrète, d'incompréhension reste très grande, et c'est aussi cela qui crée cette relation très forte avec ce public nouveau.

Dans mes souvenirs personnels, ce ne sont ni La Tempête « de » Strehler, ou le Hamlet « de » Chéreau, qui sont restés. C'étaient de grands spectacles et le souvenir en est vivace. Mais il a parfois des émotions incroyables: au Malibran, à Venise, j’ai vu la Tempête traduite en napolitain par Eduardo de Filipo, et interprétée par une troupe de marionnettistes milanais, Carlo Colla e Figli. Cette troupe célèbre, constituée vers 1800 , reprenait à l'époque les grands ballets, les grands opéras de la Scala pour un public populaire. Cette Tempête était assez rébarbative, compliquée à suivre car une seule voix enregistrée sur magnétophone tenait tous les rôles, mais à la toute fin, il s'est produit un miracle. Les Colla utilisaient une vraie machinerie, avec le pont où se tenaient quinze personnes, et un castelet gigantesque. Pendant le dernier monologue de Prospero, le castelet montait dans les cintres et, sur pont dévoilé à cet instant, on découvrait le marionnettiste, manipulateur du grand manipulateur, Prospero. Je me souviens du Lear mis en scène à la MC93 par Matthias Langhoff, avec Serge Merlin, François Chatot. Quatorze représentations avant de retourner à la poussière. Ce fut pour nous un choc immense, mais je ne me souviens plus de l'accueil qu'avait fait le public à cette mise en scène. Comme Matthias avait très peu coupé, tout le monde partait à minuit moins dix, de peur de manquer le dernier métro. Ça fait partie des joies d'être au bout de la ligne. D'un Roméo et Juliette mis en scène au conservatoire par une jeune élève, Saskia Cohen-Tanuggi, où elle avait tout donné. De Brian Cox en Titus Andronicus, et du Richard II que Deborah Warner avait monté à Bobigny. Du Marchand de Venise de Peter Sellars. 
La langue étrangère demande au spectateur un travail supplémentaire qui ajoute au mystère du théâtre. Cela demande un effort de concentration en plus, surtout en France, où on connaît peu les pièces, à la différence de l'Allemagne ou de la Russie. Autour des années 1980, on a commencé à fabriquer en Europe du théâtre jetable, prêt à consommer, qui ne «cause pas trop ». La technique du surtitrage, qu'on utilise depuis une quinzaine d'années, beaucoup plus satisfaisante que les oreillettes qu'on avait jadis au Théâtre des Nations, a permis de renouer avec le théâtre européen qui avait été rejeté des salles par cette idéologie du consommable. Dix-huit millions de tickets de théâtre par an se vendent en France, mais combien pour voir du vrai théâtre, depuis qu'on a inventé cet objet étrange qui en garde le nom mais dont je ne vois pas bien le lien à l'art ? Dans un pays qui n'aime pas le théâtre, oui, le théâtre est un combat. Jadis on pouvait monter un spectacle, engager des comédiens, faire la production, construire les décors et créer les costumes. On continue, mais maintenant il faut une pléthore de « co-producteurs » pour avoir les moyens de créer le spectacle. Si je travaille avec des équipes comme Jean-Yves Ruf ou Jean-Michel Rabeux, c'est entre autres parce qu'ils ont leur propre réseau qui permettent de créer ces spectacles... dans des conditions moyenâgeuses, avec des acteurs payés en gros ce qu'étaient payés mes parents chez Jean Dasté dans les années cinquante. Ce ne sont pas les théâtres établis en France qui participent à ces montages, mais souvent des circuits de structures modestes qui s'unissent pour monter ces spectacles, toujours chers parce qu'il faut toujours beaucoup d'acteurs pour jouer Shakespeare. Mais initier ne veut pas forcément dire rendre accessible : les metteurs en scène qui ont travaillé récemment Shakespeare en français chez nous n'ont pas cherché à le réduire, ni à le rendre plus intelligible ou accessible. Au contraire, ils se sont emparés du magma shakespearien en essayant de le replacer dans leur propre contexte, dans le magma de cette société particulièrement tumultueuse. C'est pour cela qu'on vient au théâtre. Si on a l'impression de quelque chose d'achevé à la fin de la représentation, c'est qu'il ne s'est rien passé.

Propos transcrits et résumés par D. Goy-Blanquet 